\title{
Iron Deficiency Anemia \& Adverse Events After ST Elevation Acute Myocardial Infarction
}

\section{Nighat Majeed, ${ }^{1}$ Muhammad Rizwan, ${ }^{2}$ Zartashia Samreen ${ }^{3}$}

\begin{abstract}
Objectives: Study objective was to look for the frequency of iron deficiency in ischemic heart disease patients presenting with acute ST elevation myocardial infarction and to see the association of adverse coronary events with iron deficiency among these patients

Methods: It was a cross-sectional study conducted on three hundred and seventeen patients at coronary care unit/Medical unit of services hospital Lahore. Serum ferritin, iron, and transferrin were measured by using automated immunoassays in patient admitted with acute myocardial infarction and adverse events developed after myocardial were recorded at 5 th day of admission. Frequency of iron deficiency anemia was determined in these patients. Adverse events after acute myocardial infarction such as development of recurrent MI, unstable angina, arrhythmias, pericarditis, (EF $<50 \%$ ), adverse outcomes in the form of mechanical complications (ventricular septal defect or mitral regurgitation, and significant impairment of left ventricular functions, stroke and death rate was studied in these patients. Chi-square test was used to see association of iron deficiency anemia with adverse events developed after myocardial infarction.

Results: Frequency of iron deficiency was $82 \%$ among patients suffering from acute myocardial infarction. There was significant association of anemia with Post myocardial infarction heart failure $(\mathrm{P}=0.006)$, Low EF $<50 \%(\mathrm{P}=0.00)$, increased mortality $(0.076)$ and pericarditis $(\mathrm{P}=0.069)$.Iron deficiency was associated with of adverse outcomes after myocardial infarction.

Conclusion: Increased frequency of iron deficiency anemia was recorded in patients suffering from acute myocardial infarction and it was significantly associated with the post myocardial infarction adverse events.

Keywords: Iron deficiency anemia, Acute myocardial infarction, Adverse outcomes
\end{abstract}

\section{Introduction}

$\mathrm{A}$ cute myocardial infarction is causing significant morbidity and mortality in patients suffering from cardiovascular diseases. Iron is essential for all physiological processes in body. Iron is not only required for erythropoiesis but is also important in oxygen storage \& transport, Synthesis of deoxyribonucleic acid and so for the erythropoiesis, electron transport, oxygen transport and synthesis/ degrada-

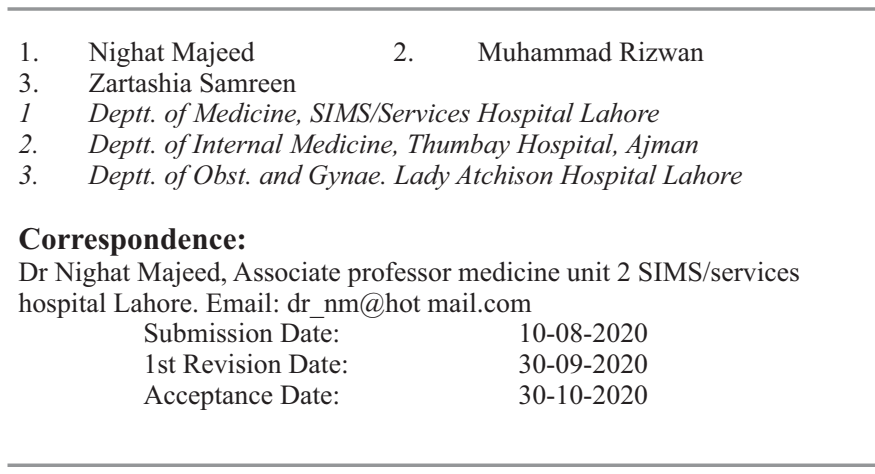

tion of muscle protein. All the muscles in body including cardiac myocytes require iron for proper functioning. ${ }^{1}$ Iron deficiency is of two types, one in which the iron stores are exhausted but the iron homeostasis is preserved, the second type of iron deficiency is called functional iron deficiency in which the total iron reserves are normal but the iron supply is not sufficient to fulfill the demands of body. ${ }^{2}$ In functional Iron deficiency value of serum ferritin is normal but the transferrin saturation is low. ${ }^{3}$

Among cardiovascular diseases iron deficiency is seen in heart failure and in patients suffering from acute myocardial infarction. ${ }^{4}$ Like many nontraditional novel cardiovascular risk factors, role of iron deficiency was studied in patients with cardiac illnesses. ${ }^{5}$ There are many pathophysiological mechanisms for anemia in coronary artery disease. The hyperdynamic state contribute to left ventricular hypertrophy and arterial wall thickness if anemia is 
not get corrected. ${ }^{6}$

Anemia is a risk factor for ischemic heart disease and mortality associated with it. ${ }^{7}$ Adverse prognosis is found in patients of anemia with acute coronary syndrome irrespective of type of anemia. ${ }^{8}$ Effect of anemia on outcome is independent of other etiological factors and it can predict the survival in patients with cardiac diseases. ${ }^{9}$ Myocardial necrosis resulting from acute obstruction of coronary artery results in acute myocardial infarction suggested by typical history ST segment elevation in two consecutive chest or limb leads or elevated cardiac biomarkers. ${ }^{10}$ Heart failure is a clinical syndrome presenting with symptoms of dyspnea, paroxysmal nocturnal dyspnea, edema feet and signs such as elevated jugular venous pressure, and bibasilar crepitation. It is caused due to structural heart disease such as ischemia or due to any functional cardiac abnormality which is causing decreased in stroke volume. ${ }^{11}$

In this study we assessed the presence of iron deficiency and its association of with adverse outcomes/ events after acute myocardial infarction. Our aim was to look for the of iron deficiency in patients of ischemic heart disease presenting with coronary ischemia and to see the association of iron deficiency with adverse coronary events in these patients.

\section{Methods}

It was an observational cross-sectional study; the study duration was twelve months. The sample size for the study was calculated by taking most probable prevalence of iron deficiency as $29 \%$ and with $95 \%$ confidence interval. Three hundred and seventeen 317 patients were included in the study. These patients were admitted in coronary care unit of services hospital Lahore from July 2018 to July 2019 with acute ST elevation myocardialinfarction? Patients with cardiomyopathies, on anticoagulation therapy, cancer and fever were excluded. Informed consent was obtained by all and ethical approval was taken from institutional review board of services hospital Lahore.

Any hemoglobin level $<12.0 \mathrm{~g} / \mathrm{dL}$ is defined as anemia. Iron deficiency anemia was defined as hemoglobin level $<12.0 \mathrm{~g} / \mathrm{dL}$ in female and $<13.5 \mathrm{~g} / \mathrm{dl}$ in male. Serum ferritin is a parameter for iron deficiency. Normal serum ferritin is $30-300 \mathrm{ng} / \mathrm{ml}$.
Serum ferritin is an acute-phase reactant, and diagnosis of iron deficiency anemia was made if patient is anemic and serum ferritin was less than $30 \mathrm{ng} / \mathrm{ml}$ or serum ferritin less than $12 \mathrm{ng} / \mathrm{dl} .^{12}$

Baseline information was taken from hospital charts. Coronary artery disease was diagnosed as patient presenting with signs/symptoms of myocardial infarction, ECG changes, raised cardiac enzymes and Troponin I levels. ${ }^{13}$ Other routine laboratory values were recorded. Complete blood count with red blood cell morphology and indices, Serum ferritin and iron was measured by using automated immunoassays on 5th day of admission. Adverse events/outcomes the patient developed after ST elevation myocardial infarction at 5 th day of admission were recorded. The complications or adverse events after myocardial infarction studied were, recurrent Myocardial Infarction MI, unstable angina, arrhythmias(premature atrial \& ventricular contraction, ventricular tachycardia, ventricular fibrillation and atrial fibrillation) stroke, pericarditis, significant impairment of left ventricular functions ( $\mathrm{EF}<50 \%)$, the mechanical complications such as ventricular septal defect or mitral regurgitation due to papillary muscle ruptured and death. ECG changes, Troponin I and echocardiography was used to diag-nose the adverse events. The definition of iron deficiency was based on serum ferritin and hemo-globin levels. ${ }^{14}$

\section{Results}

Out of three hundred and fifty patients, mean age of patients was 54 years. 53\%patients were male and $47 \%$ patients were female. Mean hemoglobin of patients was $10 \mathrm{~g} / \mathrm{dl}$ and mean serum ferritin was $25 \mathrm{ng} / \mathrm{dl}$. Mean ejection fraction of these patients was $45 \% .88 \%$ of patients were found to be anemic. $82 \%$ patients had serum ferritin less than 30ng/dl and $18 \%$ patients has more than $30 \mathrm{ng} / \mathrm{dl}$ (Table 1 )

After myocardial infarction $62.1 \%$ patient developed adverse events like arrhythmias in the form of premature ventricular contractions (35\%), atrial fibrillation (20\%), ventricular tachycardia $(23 \%)$, APC'S (10\%) and ventricular fibrillation (7\%), 23\% patient had stroke, $15.5 \%$ patient had recurrent acute myocardial infarction, $97.1 \%$ patient had unstable angina, 5\% patient died, $20.5 \%$ patient had pericarditis, $74 \%$ patient had clinical heart failure and among these $68 \%$ patient had impairment of LV functions on echocardiography (EF $<50 \%$ ) (FIG.1), $0.3 \%$ patient patients had ventricular septal defect, $1.9 \%$ patient had mitral regurgitation due to papillary 
Table 1: Descriptive Statistics of Study Population

\begin{tabular}{|c|c|c|c|c|c|c|c|c|c|}
\hline \multirow{2}{*}{$\begin{array}{c}\text { Study } \\
\text { parameters }\end{array}$} & \multirow{2}{*}{$\begin{array}{l}\mathrm{N}=\text { total } \\
\text { patients }\end{array}$} & \multirow{2}{*}{ Range } & \multirow{2}{*}{ Minimum } & \multirow{2}{*}{ Maximum } & \multirow{2}{*}{ Sum } & \multicolumn{2}{|c|}{ Mean } & \multirow{2}{*}{$\begin{array}{c}\text { Std. } \\
\text { Deviation }\end{array}$} & \multirow{2}{*}{ Variance } \\
\hline & & & & & & Statistics & Std err & & \\
\hline Age & 317 & 70 & 20 & 90 & 172.5 & 54.42 & .867 & 15.435 & 238.245 \\
\hline Hemoglobin & 317 & 8 & 6 & 14 & 3177 & 10.02 & .115 & 2.042 & 4.171 \\
\hline Serum ferritin & 317 & 152 & 4 & 156 & 8963 & 28.28 & 1.399 & 24.901 & 620.045 \\
\hline Ejection Fraction & 317 & 55 & 9 & 64 & 14405 & 45.44 & .388 & 6.913 & 47.792 \\
\hline
\end{tabular}

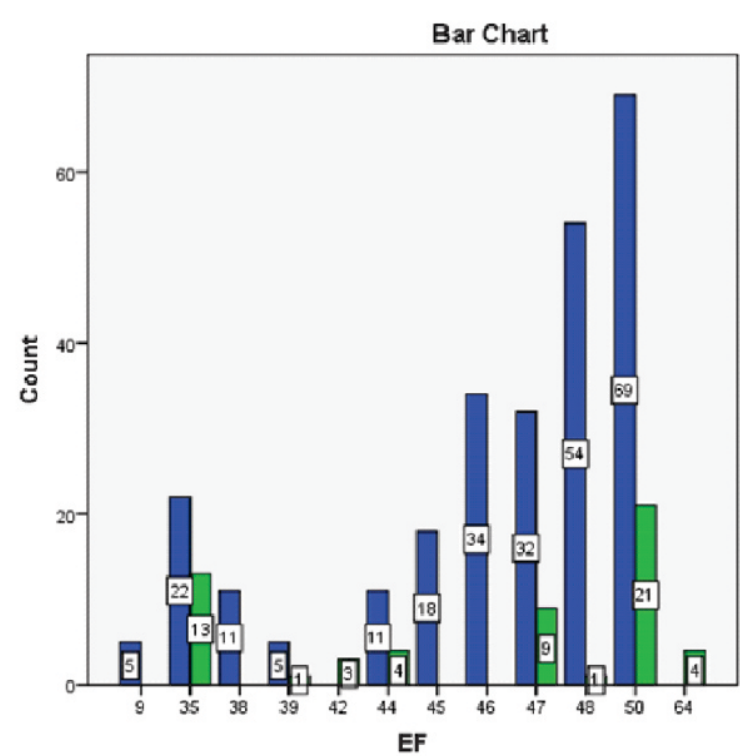

muscle ruptured. The complications are listed in
Figure 1: Serum Ferritin and Ejection Fraction $(P=0.00)$

Table: 2

Recurrent acute myocardial infarction had no significant association with anemia $(\mathrm{P}=0.12)$. There was significant association of anemia with gender and males were having the significantly low levels of serum ferritin $(P=0.07)$, patients with diabetes mellitus were not found to have significantly low hemoglobin $(\mathrm{P}=0.22)$. Stroke was not significantly related with serum ferritin levels $(p=0.77)$, increased mortality was not seen in patients who were found to be anemic and had low serum ferritin (0.076). Hypertension was significantly related with anemia $(\mathrm{P}=$ 0.006). Obesity was not significantly related with anemia $(\mathrm{P}=0.14)$.

The frequency of anemia in these patients was found to

Table 2: Anemic Patients Who Developed Complications after Myocardial Infarction

\begin{tabular}{|c|c|c|c|c|}
\hline \multirow{2}{*}{ Study parameters } & \multicolumn{2}{|c|}{ Serum Ferritin } & \multirow{2}{*}{$\begin{array}{c}\text { Total no of } \\
\text { patients }\end{array}$} & \multirow{2}{*}{ Types of Myocardial infarction } \\
\hline & $\mathrm{N}=<30 \mathrm{ng} / \mathrm{dl}$ & $\mathrm{N}=>30 \mathrm{ng} / \mathrm{dl}$ & & \\
\hline Diabetes mellitus & 123 & 30 & $\begin{array}{c}153(48.3 \%) \\
\mathrm{P}=(0.22)\end{array}$ & \multirow[t]{3}{*}{$\begin{array}{r}\text { Anterior wall myocardial infarction } \\
\text { Total No of patient }=178(56.2 \%)\end{array}$} \\
\hline Hypertension & 122 & 37 & $\begin{array}{l}159(50.2 \%) \\
\mathrm{P}=(0.006)\end{array}$ & \\
\hline Obesity & 24 & 11 & $\begin{array}{c}45(14.2 \%) \\
\mathrm{P}=(0.14)\end{array}$ & \\
\hline Unstable Angina & 224 & 52 & $\begin{array}{l}276(97.1 \%) \\
\mathrm{P}=(0.11)\end{array}$ & \multirow{3}{*}{$\begin{array}{c}\text { Inferior wall myocardial infarction } \\
\text { Total No of patient }=8(2.5 \%)\end{array}$} \\
\hline $\begin{array}{l}\text { Recurrent acute } \\
\text { Myocardial infarction }\end{array}$ & 37 & 12 & $\begin{array}{l}49(15.5 \%) \\
\mathrm{P}=(0.12)\end{array}$ & \\
\hline Death & 13 & 0 & $\begin{array}{c}13(5 \%) \\
\mathrm{P}=(0.076)\end{array}$ & \\
\hline Pericarditis & 58 & 7 & $65(20.5 \%)$ & \multirow{3}{*}{$\begin{array}{c}\text { Lateral wall myocardial infarction } \\
\text { Total No of patient }= \\
8(2.5 \%)\end{array}$} \\
\hline Clinical heart Failures & 199 & 38 & $237(74 \%)$ & \\
\hline Mechanical complications & 7 & 0 & $7(2.3 \%)$ & \\
\hline Stroke & 63 & 11 & $\begin{array}{l}74(23.3 \%) \\
\mathrm{P}=(0.77)\end{array}$ & \multirow[t]{2}{*}{$\begin{array}{l}\text { Posterior wall myocardial infarction } \\
\text { Total No of patient }=8(2.5 \%)\end{array}$} \\
\hline Arrhythmias & 159 & 38 & $197(62.1 \%)$ & \\
\hline
\end{tabular}


found with adverse events after myocardial infarction.

\section{Discussion}

Results of our study showed high frequency of iron deficiency anemia in patients with acute myocardial infarction and significant association was found between anemia and adverse events after myocardial infarction. It is shown in the previous studies that iron deficiency is associated with adverse coronary outcomes. These patients are prone to develop cardiovascular diseases in future and the role of iron replacement is not clear in these patients. ${ }^{15}$

A cross sectional study done on stable patients of ischemic heart disease by obtaining bones marrow aspirates. The results of the study showed bone marrow depletion of iron stores in patients with ischemia but not in control group. ${ }^{16}$

It has been shown in some studies that intravenous iron replacement helps to alleviate the symptoms of heart failure in patients suffering from iron deficiency. This suggests that early correction of iron deficiency after myocardial infarction can reduce the adverse outcomes in these patients. ${ }^{17}$

Iron deficiency is seen in patients with heart failure and is causing increased morbidity. The role of anemia in progression of disease is not clearly understood. Erythropoietin treatment did not improve the clinical status and associated complications. Anemia is common in patients with heart disaeses. This leads to poor outcomes in these patients. Whether to take anemia as markers of heart failure severity or a factor that mediate heart failure progression is not entirely clear. Erythropoiesisstimulating agents did not lead to clinical improvement and at times causing the serious side effects. Treatment of anemia was studied in patients both with absolute and functional iron deficiency. It is seen that treatment of iron deficiency is beneficial in patients with absolute iron deficiency and it appears to be unclear whether we should treat the functional iron deficiency or not. ${ }^{18}$ All these findings are supporting the results of our study. Hemoglobin abnormalities have been described as a cause of poor prognosis in patients with ischemic heart disease based on retrospective cohort studies. ${ }^{19}$ Our study also showed increased mortality in patients who was suffering from anemia due to iron depletion.

In a patients of chronic kidney disease hemoglobin abnormalities can lead early coronary intervention. ${ }^{20}$ It is an independent risk factor for prediction of risk of recurrent myocardial infarctions and bleeding during the procedure. Anemia is also an important factor for risk stratification of these patients. Incresed risk of recurrent ischemic events demands for early correction of anemia. ${ }^{9}$

In patients who undergo coronary stenting after myocardial infarction, hemoglobin, serum creatinine levels and ADP induced residual platelet activity is found to be an independent factors for in hospital adverse cardiovascular outcomes. ${ }^{21}$

It is an observation in a study that patients of pulmonary hypertension and heart failure and coronary artery disease undergoing bypass surgery, one third to half of patients were affected by iron deficiency and symptomatic improvements was shown after intravenous iron administration even in the absence of anemia. There is increased risk of early hospital readmission associated with absolute iron deficiency. ${ }^{22}$

The patient undergoing percutaneous coronary intervention after myocardial infarction does not get benefited from erythropoietin and increase risk of thrombotic events were observed in these patients and iron preparations are recommended only in those patients who are having the iron deficiency or the blood loss. $^{23}$

A study done in patients with heart failure and pulmonary hypertension showed that one third of patients with heart failure and fifty percent patients with pulmonary hypertension demonstrated iron deficiency. This observation suggests that iron deficiency is a risk factor for all cardiovascular events. ${ }^{8}$

Sixty one percent prevalence of iron deficiency in patients of coronary artery disease was seen and it persisted at some point in next thirty days. This effect appears to be associated with antiplatelet treatment and increased inflammation. High frequency of iron deficiency in patients of acute myocardial infarction need to deter-mine the hemorrhagic risk factors in patients. Anti-platelet treatment and subsequent coronary interven-tion can be a cause of iron deficiency in these patients. Also there is a need to 
required for those patients who are requiring early coronary intervention. ${ }^{7}$

It has been shown that red cell distribution width is a risk factor and is poor prognostic factor after coronary events. Ferritin level is a marker of inflammation and poor prognostic factor for left ventricular systolic function. Coronaryy artery disease is associated with increase in other markers of inflammation such as C reactive protein. ${ }^{24}$

\section{Conclusion}

The frequency of iron deficiency anemia is very high in patients suffering from acute myocardial infarction and it is associated with significantly increased complications after myocardial infarction.

Limitations of Study: The patients were only followed during hospital stay. Further studies are required for post myocardial infarction follow up and risk stratification in patients with iron deficiency anemia.

\section{Author's Contribution}

NM: Data Collection

MR: Research Proposal, writing discussion

ZS: Statistical Analysis \& Research Proposal writing

\section{References}

1. Zeller T, Waldeyer C, Ojeda F, Schnabel R, Schäfer S, Altay A, et al. Adverse Outcome Prediction of Iron Deficiency in Patients with Acute Coronary Syndrome. Biomolecules [Internet]. 2018 Jul 20 [cited 2019 Aug 5];8(3):60.

2. Litton E, Lim J. Iron Metabolism: An Emerging Therapeutic Target in Critical Illness. Crit Care. 2019; 23(1):1-8.

3. Muñoz M, Gómez-Ramírez S, Besser M, Pavía J, Gomollón F, Liumbruno GM, et al. Current misconceptions in diagnosis and management of iron deficiency. Blood Transfus. 2017;15(5):422-37.

4. Meroño O, Cladellas M, Ribas-Barquet N, Poveda P, Recasens L, Bazán V, et al. Iron Deficiency Is a Determinant of Functional Capacity and Healthrelated Quality of Life 30 Days After an Acute Coronary Syndrome. Rev Española Cardiol. 2017; 70(5): 363-70.

5. Oh HL, Lee JA, Kim DH, Lim JS. Reference values for serum ferritin and percentage of transferrin saturation in Korean children and adolescents. Blood Res. 2018;53(1):18-24.
6. Rymer JA, Rao S V. Anemia and coronary artery disease. Coron Artery Dis;29(2):1.

7. Meroño O, Cladellas M, Ribas-Barquet N, Recasens L, Bazán V, Comín-Colet J. Iron Deficiency in Patients With Acute Coronary Syndrome: Prevalence and Predisposing Factors. Rev Española Cardiol. 2016 Jun 1;69(6):615-7.

8. P. B, V.R. S, S.S. O, K.P. A. A prospective study on prevalence and causes of anaemia in patients with acute coronary syndrome. Vol. 10, Journal of Clinical and Diagnostic Research. 2016. p. OC01-5.

9. Stucchi M, Cantoni S, Piccinelli E, Savonitto S, Morici N. Anemia and acute coronary syndrome: current perspectives. Vasc Health Risk Manag. 2018 May 30; Volume 14:109-18.

10. Saleh M, Ambrose JA. Understanding myocardial infarction [version 1; referees: 2 approved]. F1000 Research. 2018;7(0):1-8.

11. Kurmani S, Squire I. Acute Heart Failure: Definition, Classification and Epidemiology. Curr Heart Fail Rep . 2017;14(5):385-92.

12. Lloyd E. Damon M, Charalambos Andreadis M. Blood disorder. Current medical diagnosis and ttreattment.. CMDT . 59th ed. New York Mc Graw Hill 2020;13 p. 515.

13. Buccheri S, D'Arrigo P, Franchina G, Capodanno D. Risk stratification in patients with coronary artery disease: A practical walkthrough in the landscape of prognostic risk models. Interv Cardiol Rev. 2018; 13(3): 112-20.

14. Karakochuk CD, Hess SY, Moorthy D, Namaste S, Parker ME, Rappaport AI, et al. Measurement and interpretation of hemoglobin concentration in clinical and field settings: a narrative review. Ann N Y Acad Sci. 2019;1450:126-46.

15. Jankowska EA, Tkaczyszyn M, Suchocki T, Drozd M, von Haehling S, Doehner W, et al. Effects of intravenous iron therapy in iron-deficient patients with systolic heart failure: a meta-analysis of randomized controlled trials. European Journal of Heart Failure. 2016; Vol 18: p. 786-95.

16. von Haehling S, Ebner N, Evertz R, Ponikowski P, Anker SD. Iron Deficiency in Heart Failure: An Overview. JACC Hear Fail. 2019; 7(1):36-46.

17. Anand IS, Gupta P. Anemia and Iron Deficiency in Heart Failure. Circulation. 2018 Jul 3;138(1):80-98.

18. Abebe TB, Gebreyohannes EA, Bhagavathula AS, Tefera YG, Abegaz TM. Anemia in severe heart failure patients: Does it predict prognosis? BMC Cardiovasc Disord. 2017;17(1):1-7.

19. Lee G, Choi S, Kim K, Yun JM, Son JS, Jeong SM, et 
al. Association of hemoglobin concentration and its change with cardiovascular and all-cause mortality, Journal of the American Heart Association. 2018; Vol. 7: 3041565.

20. Lakhal-Littleton S. Mechanisms of cardiac iron homeostasis and their importance to heart function. Free Radic Biol Med. 2019;133:234-7.

21. Mansurova JA, Karazhanova LK. Independent Predictors of Adverse Cardiovascular Events in Patients With Acute Coronary Syndrome After Percutaneous Coronary Intervention During Hospitalization. Kardiologiia. 2018 Dec 25;58(12):22-9.
22. von Haehling S, Jankowska EA, van Veldhuisen DJ, Ponikowski P, Anker SD. Iron deficiency and cardiovascular disease. Nat Rev Cardiol. 2015 Nov 21;12(11):659-69.

23. Budzianowski J, Pieszko K, Burchardt P, Rzeźniczak J, Hiczkiewicz J. The Role of Hematological Indices in Patients with Acute Coronary Syndrome. Dis Markers. 2017;2017:1-9

24. Abtahi F, Abdi A, Jamshidi S, Karimi M, BabaeiBeigi MA, Attar A. Global longitudinal strain as an Indicator of cardiac Iron overload in thalassemia patients. Cardiovasc Ultrasound. 2019;17(1):1-6. 